\title{
THE EFFECT OF 1-HYDROXYPHENAZINE AND PYO- CYANIN FROM PSEUDOMONAS AERUGINOSA ON MAMMALIAN CELL RESPIRATION
}

\author{
D. E. S. Stewart-Tull and AnN V. Armstrong \\ Microbiology Department, Alexander Stone Building, Glasgow University, \\ Garscube Estate, Bearsden, Glasgow
}

IN 1953 Cruickshank and Lowbury found that pyocyanin was toxic to human skin cells and leucocytes in vitro, and suggested that this might explain the local pathogenic effects caused by Pseudomonas aeruginosa in burns.

Previously, Jackson, Lowbury and Topley (1951) had found that pyocyanin was nontoxic when injected into the skin of animals. Berk, Nelson and Pickett $(1960 a$ and $b)$ studied the interaction between Ps. aeruginosa and mouse peritoneal monocytes. The oxygen uptake by the mixture was greater than that attributable to an additive effect of bacterium and monocyte alone. Similar results were obtained with heat-killed monocytes, kidney homogenates or HeLa cells; it was concluded that the organism metabolised cellular materials. It was also shown that the addition of heat-killed cells of Ps. aeruginosa inhibited the endogenous and succinoxidase activities of mouse monocytes, but did not affect their cytochrome oxidase activity. Nelson and Berk (1960) extended this work and found that not only the whole organism but also its component parts inhibited the respiration of mouse monocytes, spleen and HeLa cells.

Armstrong, Stewart-Tull and Roberts (1971) examined the effect on liver mitochondrial respiration of pyocyanin and its derivatives prepared either from Ps. aeruginosa culture fluids or by chemical synthesis. It was shown that 1-hydroxyphenazine completely inhibited the uptake of oxygen by suspensions of mouse liver mitochondria. Later, it was shown that 1-hydroxyphenazine acted at the site of ubiquinone-cytochrome $b$ within the electron transport chain (Armstrong and Stewart-Tull, 1971). However, these investigations did not reveal whether 1-hydroxyphenazine would inhibit the respiration of intact cells, and it was decided to explore the effect of 1-hydroxyphenazine and pyocyanin on the respiration of intact mammalian cells.

\section{MATERIALS AND METHODS}

Preparation of pseudomonas fractions and chemical synthesis of pyocyanin and 1-hydroxyphenazine

The methods used were identical with those described by Armstrong et al.

Preparation of suspensions of mouse liver and hamster kidney cells

Two cell-lines were used in this investigation: (a) L" $\mathrm{L}$ ", derived from mouse liver and (b) BHK strain $\mathrm{C} 13$, derived from hamster kidney. The cells were grown in Eagle's complete medium (Eagle, 1955a, $b$ and $c$ ) as modified by Paul (1959). Burler bottles containing $200 \mathrm{ml}$

Received 17 July 1971; accepted 18 Aug. 1971.

J. MFD. MICROBIOL.-VOL. 5 (1972) 
Eagle's medium were seeded with approximately $20 \times 10^{6}$ cells and gassed with $\mathrm{CO}_{2}$. After 3 days at $37^{\circ} \mathrm{C}$ the cells were harvested from the tissue cultures.

(a) The contents of burler bottles containing L"S" cells in suspension were removed aseptically and centrifuged at 1000 r.p.m. for 5 min. The pellet was resuspended in Eagle's medium minus glucose; substrate was added during the measurement of respiratory activity.

(b) After removal of the medium the monolayer of BHK strain C13 cells was washed with $25 \mathrm{ml}$ trypsin-Versene solution. The washed monolayer was suspended in $25 \mathrm{ml}$ trypsinversene solution and centrifuged at 1000 r.p.m. for $5 \mathrm{~min}$. The pellet was resuspended in Eagle's medium minus glucose.

\section{Preparation of a suspension of macrophage cells from the peritoneal exudate of a guinea-pig}

Sterile paraffin oil $(20 \mathrm{ml})$ was injected intraperitoneally into an albino guinea-pig. After 4 days the animal was killed and $200 \mathrm{ml}$ Hanks' fluid containing 20 IU non-phenolised heparin per $\mathrm{ml}$ was injected into the peritoneal cavity. The peritoneal washings were aspirated, pooled and centrifuged at 1000 r.p.m. for $10 \mathrm{~min}$. at $4^{\circ} \mathrm{C}$. The pellet was resuspended in Hendry's sucrose phosphate buffer, $p \mathbf{H} 7 \cdot 3$.

\section{Warburg manometry and oxygen polarography}

The procedures for measuring cell respiration were those described by Armstrong et al.

Determination of the optimal number of tissue culture cells for manometric measurements of respiration. Variable numbers of cells, from $17 \times 10^{6}$ to $80 \times 10^{6}$, were suspended in $2.5 \mathrm{ml}$ of Eagle's medium minus glucose. Glucose $(0.3 \mathrm{ml}$ containing $5.0 \mathrm{mg})$ was added from the side-arm; $0.2 \mathrm{ml}$ of $0.1 \mathrm{M}-\mathrm{NaOH}$ was contained in the centre pot of the Warburg flask.

The effect of pseudomonas fractions on mouse liver and hamster kidney cells. The cell suspension $(1.8 \mathrm{ml})$ and $0.5 \mathrm{ml}$ oxidisable carbohydrate (either $5 \mathrm{mg}$ glucose or $0.2 \mathrm{M}$ sodium succinate) were placed in the main well of the Warburg flask. The pseudomonas fraction $(0.5 \mathrm{ml})$ was placed in the side-arm, and $0.2 \mathrm{ml}$ of $0.1 \mathrm{M}-\mathrm{NaOH}$ in the centre pot. The oxidation of the substrates was measured at $37^{\circ} \mathrm{C}$.

The effect of pseudomonas fractions on the respiration of guinea-pig macrophages. The respiration of peritoneal macrophages was measured in the oxygen polarograph with either $0 \cdot 2 \mathrm{M}$ sodium succinate or $0.2 \mathrm{M}$ glucose as substrate. Pyocyanin or 1-hydroxyphenazine was added to respiring macrophages or was pre-incubated with the macrophages for periods up to $2 \mathrm{hr}$ before measurement of respiratory activity.

\section{The in-vivo effect of Pseudomonas aeruginosa NCTC6750, 1-hydroxyphenazine and pyocyanin on mammalian cell respiration}

Groups of six mice each received by intraperitoneal injection $1 \times 10^{8} P$ s. aeruginosa NCTC6750 organisms. The test and control mice were killed by cervical dislocation $17 \mathrm{hr}$ after the injection. The livers were removed, mitochondrial suspensions were prepared and respiratory activity was measured.

Pyocyanin (PF 49) or 1-hydroxyphenazine (PF 48) was injected intravenously or intraperitoneally into groups of six mice. Mitochondrial suspensions were prepared from animals that died or were killed, and their respiration was measured in the oxygen polarograph. The total volume in each test was $3 \mathrm{ml}$, consisting of $2.5 \mathrm{ml}$ Hendry's sucrose phosphate buffer, $0.3 \mathrm{ml}$ of $0.2 \mathrm{M}$ sodium succinate and $0.2 \mathrm{ml}$ mitochondrial suspension.

\section{RESULTS}

The inhibition of respiration in mouse liver and hamster kidney tissue-culture cells by pseudomonas fractions

Preliminary experiments were done to determine the optimal number of mouse liver ( $\mathrm{L}$ " $\mathrm{S}$ ") and hamster kidney (BHK strain $\mathrm{C13}$ ) cells that gave a 
measurable rate of respiration per Warburg flask; optimal conditions were obtained with $47 \times 10^{6}$ or more cells per flask.

The uptake of oxygen by $L$ " $S$ " cells utilising sodium succinate was reduced by the pigment-containing supernatant culture fluid of Ps. aeruginosa (PF 2) and also by the sediment of a chloroform extract (PF 30) to $18 \mu 1$ in 90 min., whereas in control flasks it was $240 \mu \mathrm{l}$ in $90 \mathrm{~min}$. However, the uptake of oxygen by the same tissue-culture cells utilising glucose was not inhibited by these pseudomonas fractions (fig. 1).

The BHK cells were found to utilise glucose but not succinate. Both PF 2 and PF 30 reduced the uptake of oxygen by these cells when they were utilising glucose to $160 \mu \mathrm{l}$ in $100 \mathrm{~min}$., whereas in the control flask it was $220 \mu \mathrm{l}$ (fig. 1).

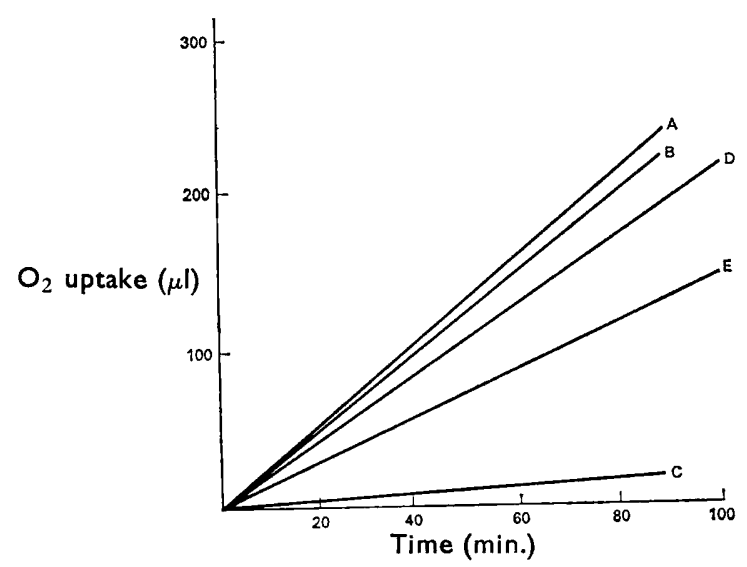

Fig. 1.-The effect of pseudomonas fractions on the respiration of mouse liver, $L$ " $S$ ", and baby hamster kidney BHK strain $\mathrm{C} 13$ tissue-culture cells. A: Control Warburg flask containing $\mathrm{L}$ "S" cells utilising sodium succinate or glucose; $B$ : flask containing $\mathrm{L}$ " $\mathrm{S}$ " cells utilising glucose plus PF 2 or PF 30; C: flask containing $L$ "S" cells utilising succinate plus PF 2 or PF $30 ; D$ : control flask containing BHK cells utilising glucose; $\mathrm{E}$ : flask containing BHK cells utilising glucose plus PF 2 or PF 30 . PF 2, a crude fraction containing 1-hydroxyphenazine prepared from Ps. aeruginosa culture fluid. PF 30, the sediment of a chloroform extract of Ps. aeruginosa culture fluid.

\section{The action of 1-hydroxyphenazine and pyocyanin on macrophage respiration}

The effect of pseudomonas fractions on the uptake of oxygen per minute by peritoneal macrophages was measured in the polarograph. When $75 \mu \mathrm{g}$ of 1-hydroxyphenazine (PF 43 or PF 48) or pyocyanin (PF 42 or PF 49) was added to macrophages utilising $0 \cdot 2 \mathrm{M}$ sodium succinate respiratory activity was not reduced. However, the addition of four times the amount of 1-hydroxyphenazine to respiring macrophages utilising $0 \cdot 2 \mathrm{M}$ glucose caused a 77 per cent. reduction in respiratory activity (fig. 2).

Peritoneal macrophages were incubated at $37^{\circ} \mathrm{C}$ in the presence of approximately half the quantity of chemical, namely, $33 \mu \mathrm{g}$ of 1-hydroxyphenazine or $33 \mu \mathrm{g}$ of pyocyanin. The uptake of oxygen by macrophages utilising glucose as substrate was measured in the polarograph after variable periods of pre-treatment with the chemicals. Figure 3 shows that there was no significant difference 
in the percentage reduction of oxygen uptake by macrophages treated for 1 , $1 \frac{1}{2}$ or $2 \mathrm{hr}$ with 1-hydroxyphenazine. A similar result was found with macrophages treated with pyocyanin. However, whereas 1-hydroxyphenazine caused 54-56 per cent. inhibition of macrophage respiration, pyocyanin caused only 8-31 per cent. inhibition.

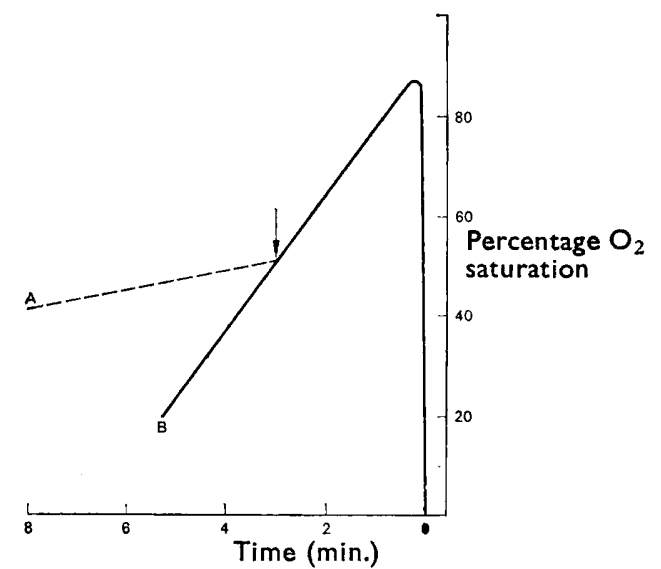

FIG. 2.-The effect of 1-hydroxyphenazine (PF 48) on the respiration of guinea-pig peritoneal macrophages measured in the oxygen polarograph. A: after the addition of $300 \mu \mathrm{g} 1$-hydroxyphenazine; B: control without 1-hydroxyphenazine. Fractions were added at the point marked with an arrow.

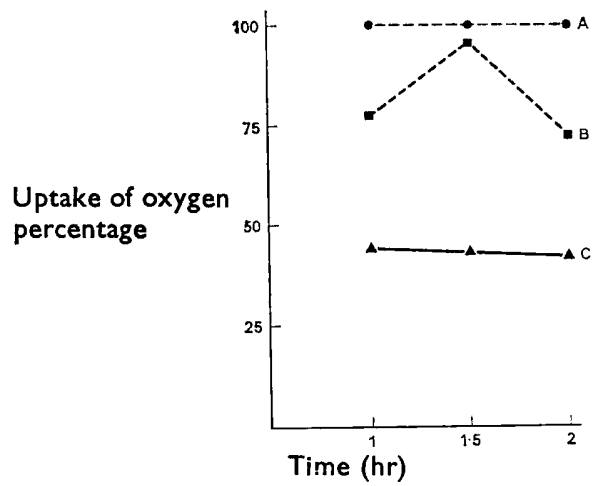

FIG. 3.-The effect of pre-incubation with 1-hydroxyphenazine (PF 48) and pyocyanin (PF 49) on the respiration of guinea-pig peritoneal macrophages measured in the oxygen polarograph. A: control macrophages; $B$ : pyocyanin-treated macrophages; $C$ : 1-hydroxyphenazine-treated macrophages.

The respiratory activity of liver cell mitochondria from infected mice

Mice that received $28 \times 10^{8}$ or $5.6 \times 10^{8} P$ s. aeruginosa NCTC6750 organisms died within $24 \mathrm{hr}$ of the injection; none died after receiving $22 \times 10^{6}$ or $4 \times 10^{7}$ organisms. It was decided to inject $1 \times 10^{8}$ organisms, since this number was about 1 LD50. The average uptake of oxygen by isolated liver mitochondria from uninfected animals was $350 \mu \mathrm{l}$ and from infected animals $260 \mu \mathrm{l}-\mathrm{a}$ reduction of 25 per cent. in the respiratory activity. 
The respiration of liver cell mitochondria from mice given an injection of pyocyanin ( $P F 49)$ or 1-hydroxyphenazine ( $P F 48)$

Mice given an intravenous injection of $0.2 \mathrm{ml}$ saline containing $6.6 \mathrm{mg}$ pyocyanin (PF 49) or $2 \mathrm{mg}$ 1-hydroxyphenazine died within $2 \mathrm{~min}$. of the injection. During the preparation of mitochondrial suspensions from the liver of these animals it was found that the supernatant fluid from the disintegrated liver from pyocyanin-treated animals was pale green; from 1-hydroxyphenazinetreated animals it was brownish-yellow. The polarograph results indicated that

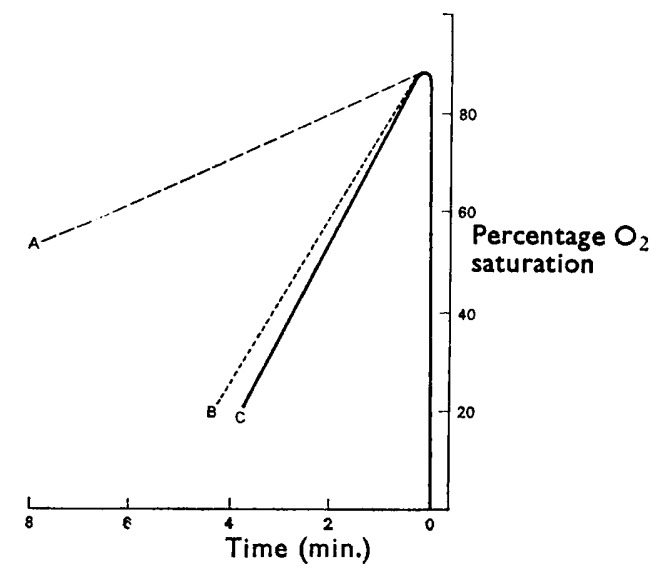

FIG. 4.-The effect of 1-hydroxyphenazine (PF 48) on mouse liver mitochondria in vivo. A: liver mitochondria from mice given an intravenous injection of $1 \mathrm{mg} \mathrm{1-hydroxyphenazine;} \mathrm{B:} \mathrm{liver}$ mitochondria from mice given an intraperitoneal injection of $2 \mathrm{mg} 1$-hydroxyphenazine; $\mathrm{C}$ : liver mitochondria from control animals.

there was a reduction in the respiratory activity of the isolated mitochondria by 36.0 per cent. in 1-hydroxyphenazine-treated animals and by 41.0 per cent. in pyocyanin-treated animals. The uptake of oxygen by mitochondria from animals killed after $3 \mathrm{hr}$, utilising sodium succinate as substrate, is shown in fig. 4. It was apparent that the intravenous injection of $1 \mathrm{mg}$ of 1-hydroxyphenazine caused a 59 per cent. reduction in mitochondrial respiratory activity, whereas the intraperitoneal injection of $2 \mathrm{mg}$ of 1-hydroxyphenazine caused only an 8 per cent. reduction. On the other hand, pyocyanin $(6.6 \mathrm{mg})$ caused a 19 per cent. reduction in the respiratory activity of mouse liver mitochondria obtained from animals that died $10 \mathrm{~min}$. after intraperitoneal injection.

\section{DISCUSSION}

In previous communications Armstrong et al. (1971) showed that 1hydroxyphenazine inhibited mitochondrial respiration. It was suggested that 1-hydroxyphenazine might act as an "electron shunt" at the site of ubiquinone-cytochrome $b$. However, no evidence was presented to show that 1-hydroxyphenazine could traverse the intact cell membrane.

The use of mouse liver ( $\mathrm{L}$ " $\mathrm{S}$ ") and baby hamster kidney (BHK strain C13) tissue cultures simulated to some extent the permeability barrier of the animal cells. The results indicated that the pigment-containing fraction (PF 2) obtained 
from Ps. aeruginosa culture supernatant fluid and also the sediment of a chloroform extract (PF 30) inhibited the uptake of oxygen by $L$ " $S$ " cells respiring on sodium succinate. The BHK strain C13 cells were similarly inhibited when respiring on glucose. The variable response of the tissue culture to utilisation of sodium succinate or glucose has also been observed by Dr C. G. Gemmell (personal communication). It would seem that the age of the cells, method of suspension preparation, and pretreatment with the chemicals may alter the response to a particular substrate.

It was noticed that the addition of $75 \mu \mathrm{g}$ of pseudomonas fractions (PF 42, PF 43, PF 48 or PF 49) to respiring guinea-pig peritoneal macrophages did not cause any inhibition of respiration. However, this situation was reversed when much larger amounts of 1-hydroxyphenazine $(300 \mu \mathrm{g})$ were added or the cells were pre-incubated for 1-2 hr with $33 \mu \mathrm{g}$ of 1-hydroxyphenazine or pyocyanin. It was interesting that pyocyanin was found to have an inhibitory effect on the peritoneal macrophages. These results might indicate that pyocyanin was altering the cell membrane and impeding the permeation of the substrate into the cell. Armstrong et al. showed that pyocyanin did not possess any inhibitory activity against liver cell mitochondria utilising sodium succinate. To determine whether pyocyanin affected the permeability of the cell membrane and not the mitochondrial membrane, in-vivo experiments were done. Mice were given an injection of 1-hydroxyphenazine and pyocyanin, and subsequently the respiratory activity of the liver cell mitochondria was determined. It was significant that the intravenous injection of pyocyanin caused a 41 per cent. reduction in respiratory activity - a similar effect to that of 1-hydroxyphenazine. It was also shown (fig. 4) that the maximum reduction was obtained with liver cell mitochondria from mice given 1-hydroxyphenazine by intravenous injection. These results indicate that pyocyanin does not have a selective effect against the cell membrane affecting substrate permeability. However, Armstrong and Stewart-Tull (1971) suggested that pyocyanin was a protoxic substance activated by a demethylase to yield the inhibitory 1-hydroxyphenazine. The results obtained with mouse liver L" S", hamster kidney (BHK strain C13) and guineapig peritoneal macrophages, together with the liver cell mitochondria prepared from mice after injection of pseudomonas fractions, support this hypothesis. In addition, a similar effect was observed when mice were infected with Ps. aeruginosa NCTC6750. Conclusive evidence to prove this hypothesis would be obtained by observing the intracellular metabolism of pyocyanin.

The mechanism of Ps. aeruginosa pathogenicity is complex and, although it is apparent that 1-hydroxyphenazine causes inhibition of respiration in an experimental model, the control of this process may not be simple in an infection. The results indicate that there is an inhibitory effect on both cytoplasmic and mitochondrial respiration, and the extent of such inhibition and cytolysis is controlled by the amount of chemical absorbed by the cells and the duration of exposure. This could explain the persistence of Ps. aeruginosa in burns since lysis and regeneration of macrophages would occur continuously. On the other hand, it could also explain why Ps. aeruginosa infections do not, in general, have a high mortality rate, but are nevertheless persistent. 


\section{SUMMARY}

Since 1-hydroxyphenazine was found to inhibit mitochondrial respiration, attempts were made to determine whether this material would affect whole cells. Oxygen uptake by mouse liver L" $S$ " cells, hamster kidney cells (BHK strain C13) and guinea-pig peritoneal macrophages was inhibited by 1-hydroxyphenazine and pyocyanin. In-vivo experiments confirmed that these compounds permeated the cell membrane. Pyocyanin did not inhibit mitochondrial respiration, and the hypothesis was put forward that this compound is acted on by a demethylase to produce the inhibitory 1-hydroxyphenazine and thus cause inhibition of cell respiration.

\section{REFERENCES}

Armstrong, ANN V., AND Stewart-Tull, D. E. S. 1971. The site of the activity of extracellular products of Pseudomonas aeruginosa in the electron-transport chain in mammalian cell respiration. J. Med. Microbiol., 4, 263.

Armstrong, ANn V., Stewart-Tull, D. E. S., AND Roberts, J. S. 1971. Characterisation of the Pseudomonas aeruginosa factor that inhibits mouse-liver mitochondrial respiration. J. Med. Microbiol., 4, 249.

Berk, R., Nelson, E. L., AND Pickett, M. J. 1960a. Studies on mechanisms of cellular immunity. I. Observations on the metabolism of mouse monocytes. J. Infect. Dis., 107, 175.

Berk, R., Nelson, E. L., AND Picketr, M. J. 1960b. Studies on mechanisms of cellular immunity. II. Observations on the interaction of Pseudomonas aeruginosa with various mammalian cells and fluids. J. Infect. Dis., 107, 183.

Cruickshank, C. N. D., AND LowbURY, E. J. L. 1953. The effect of pyocyanin on human skin cells and leucocytes. Br. J. Exp. Path., 34, 583.

EAGLE, H. 1955a. The specific amino acid requirements of a mammalian cell (strain L) in tissue culture. J. Biol. Chem., 214, 839.

EAGLE, H. 1955b. The specific amino acid requirements of a human carcinoma cell (strain HeLa) in tissue culture. J. Exp. Med., 102, 37.

EAGLE, H. 1955c. The minimum vitamin requirements of the $\mathrm{L}$ and HeLa cells in tissue culture, the production of specific vitamin deficiencies, and their cure. J. Exp. Med., $102,595$.

Jackson, D. M., Lowbury, E. J. L., AND Topley, Elizabeth 1951. Pseudomonas pyocyanea in burns. Its rôle as a pathogen and the value of local polymyxin therapy. Lancet, 2 , 137.

Nelson, E. L., AND Berk, R. S. 1960. Irradiation, immunization and sensitivity to toxic substances: considerations in a concept of cellular immunity. Ann. N.Y. Acad. Sci., $88,1246$.

Paul, J. 1959. Cell and tissue culture, Edinburgh, p. 78. 